\title{
SNARE proteins and caveolin-1 in stallion spermatozoa: possible implications for fertility
}

\author{
Sandra Gamboa ${ }^{\mathrm{a}}$, João Ramalho-Santos ${ }^{\mathrm{b}, *}$ \\ aAnimal Reproduction Laboratory, Department of Zootechnic Sciences, Agricultural School, \\ Polytechnic Institute of Coimbra, Bencanta, 3040-316 Coimbra, Portugal \\ ${ }^{\mathrm{b}}$ Department of Zoology, Center for Neuroscience and Cell Biology of Coimbra, \\ University of Coimbra, 3004-517 Coimbra, Portugal
}

Received 21 May 2004; received in revised form 25 November 2004; accepted 30 November 2004

\begin{abstract}
Proteins implicated in the "SNARE hypothesis" for membrane fusion have been characterized in the acrosome of several mammalian species, and a functional role for these proteins during the acrosome reaction has been proposed. We have investigated the presence of SNAREs in equine sperm, using semen samples obtained from stallions with varying fertility. Immunocytochemical analysis revealed that members of different SNARE families can be detected on the acrosome of equine sperm, notably in the acrosomal cap and equatorial segment. These proteins include the tSNARE syntaxin, the v-SNARE synaptobrevin/VAMP, the calcium sensor synaptotagmin, and the ATPase NSF. Also present is caveolin-1, a component of lipid rafts. Stallions with fertility problems presented the worst quality of sperm and acrosomal membrane, and had less sperm cells stained positively for SNAREs and caveolin-1, than sperm from fertile donors $(p<0.001)$. Ubiquitin surface staining was also performed and it seemed to inversely correlate with stallion fertility, supporting data obtained with the negative staining technique. A male-related problem was confirmed when mares that had failed to impregnate with samples from an infertile stallion were successfully inseminated with sperm from a fertile donor. Furthermore NSF, synaptotagmin and caveolin- 1 staining seemed to be useful in predicting stallion fertility, i.e. significantly more sperm cells stained positively for these proteins in samples from fertile males. Although these results need to be expanded on a larger scale,
\end{abstract}

* Corresponding author. Tel.: +351 239 834729/919588244; fax: +351 239826798 .

E-mail address: jramalho@ci.uc.pt (J. Ramalho-Santos). 
they suggest that acrosomal and surface staining of equine sperm with novel probes may constitute useful tools in predicting stallion fertility.

(C) 2004 Elsevier Inc. All rights reserved.

Keywords: Acrosome reaction; Gamete biology; Sperm; Fertilization; Equine

\section{Introduction}

One of the most important problems in horse breeding is the prediction of stallion fertility. Seminal and behavioural parameters routinely used to access and predict stallion fertility have a limited capacity for general infertility detection. Subfertile or infertile males can present normal semen profiles, while fertile stallions can have abnormal ones, given that a sperm population is very heterogeneous, and probably only a minority of cells are actually required to be functional in order for fertilization to take place [1]. Various laboratories have developed new methods for the evaluation of stallion breeding capacity, but a standardized technique that fits the majority of stallions is still not well-defined.

Sperm function, including proper sperm-zona pellucida (ZP) binding, acrosome reaction (AR), binding of the spermatozoon to the oocyte plasma membrane and spermegg fusion, is paramount for fertility. The acrosome reaction is a regulated exocytotic event that involves fusion of the apical sperm plasma membrane and the outer acrosome membrane at multiple sites, resulting in the formation of mixed vesicles that disperse the acrosomal content. The molecular mechanisms involved are still not well-known, but it is reasonable to assume that acrosomal exocytosis is similar to other calcium-triggered secretory events [2,3]. Fusion of biological membranes requires specific proteins, and various protein-mediated membrane merging models have emerged [4]. SNARE proteins (soluble NSF attachment protein receptors) are good candidates for universal fusion mediators in the secretory pathway, and form a fusion complex, consisting of a target $\mathrm{t}$ SNARE, such as syntaxin, and a vesicle v-SNARE, such as vesicle-associated membrane protein (VAMP)/synaptobrevin. Neural SNAREs assemble spontaneously into stable complexes that can be disassembled by the concerted action of the conserved cytosolic ATPase NSF (soluble $N$-ethylmaleimide-sensitive fusion protein) and the adaptor attachment proteins $\alpha / \beta$ - and $\gamma$-SNAP $[5,6]$. In regulated exocytosis the SNARE complex seems to be activated by calcium [7], and the t-SNAREs SNAP25 and syntaxin-1 interact with the calcium sensor synaptotagmin in a calcium-dependent manner [5,8]. Recently, SNARE proteins were identified on the acrosome of mammalian sperm cells ([3,9-12]; for a comprehensive review see [13]). These sperm proteins modulate secretion during the AR, and members of the synaptotagmin family are also present on the sperm head $[3,14,15]$. On the other hand, spermatozoa must also develop and retain a proper distribution of proteins and lipids in the plasma and acrosomal membranes, until membrane fusion can take place [16]. Mammalian sperm exhibit surface component regionalization related to plasmamembrane domains [17] and to regional diffusibility [18-20]. Detergent-insoluble lateral membrane specializations, named caveolae or rafts (glycosphingolipid-cholesterol microdomains), function in the sorting and transport of lipids and proteins in cellular membranes, forming a multimolecular signalling complex [21,22]. Caveolin-1, 
a cholesterol-binding protein [23], is considered the structural component responsible for the morphology of caveolae, and a key raft organizer [21,24]. Very recently, caveolin-1 was also identified in mature mouse and guinea pig sperm $[25,26]$.

The aim of the present study was to investigate the presence of SNAREs, SNAREassociated proteins and caveolin-1 in stallion sperm, as well as to correlate the number of sperm cells positive for each protein with stallion fertility, in order to determine if this approach with novel probes could be used as a predictive tool in the field. On the other hand, while functionally important proteins are predicted to be associated with functional spermatozoa, surface sperm ubiquitination has been described as a phenomenon that labels defective spermatozoa, whether those defects are obvious at the morphological level or not [27-30]. Therefore, we have also investigated the surface ubiquitination of stallion sperm cells of varied fertility. This study thus focuses on a comprehensive dual analysis of stallion fertility, using both markers for defective (ubiquitin) and functional (SNARE-related proteins, caveolin) sperm in the same semen samples. We have also compared these novel methodologies with classic assessments of stallion sperm.

\section{Materials and methods}

\subsection{Antibodies and probes}

Antibodies specific for syntaxin 1 (neural forms 1A and 1B), VAMP/synaptobrevin and NSF were obtained from Synaptic Systems (Göttingen, Germany), a polyclonal antisynaptotagmin I was a kind gift from Dr. Gary Wessel (Brown University), and a synaptotagmin I monoclonal antibody was also obtained from Synaptic Systems. Anticaveolin 1 was obtained from Santa Cruz Biotechnology (Santa Cruz, CA, USA) and antiubiquitin was obtained from Sigma (St. Louis, MO, USA). FITC-conjugated pea agglutinin PSA (Pisum sativum lectin) was also obtained from Sigma and Propidium Iodide (DNA stain) was purchased from Molecular Probes Inc. (Eugene, OR, USA). Fluorescein (FITC)conjugated secondary antibodies were obtained from Zymed (San Francisco, CA, USA).

\subsection{Semen collection and assessment of semen quality}

The study was performed during the breeding season (February to July-crescent day light period) and the bulk of semen samples used were obtained from four stallions (A-D) housed at the Agricultural School, Polytechnic Institute of Coimbra, (Coimbra, Portugal), a region with a mediterranean climate. These stallions were considered representative from a population of eight stallions analysed for SNAREs, caveolin-1 and ubiquitin. The males were evaluated according to the protocol developed by Palmer and Fauquenot [31] and previously classified as fertile (stallions A and B) or subfertile (stallions $\mathrm{C}$ and $\mathrm{D}$ ). Additionally, stallion A (Anglo-Arab, 16 years old) was classified as fertile based on fertility rates $(62.5-95 \%)$ obtained in the past four breeding seasons, with an average of 1.5-2.2 heat cycles per pregnancy. Stallion D (Hannoverian, 19 years old), a male with a history of fertility, had been experiencing fertility problems that persisted during this study. Stallion B (Lusitano, 20 years old) and C (Sorraia, 4 years old) did not have reproductive 
histories. In addition, samples were collected from three other stallions (three to five samples per male) which were, however, not available for direct fertility assessment by mare insemination during the period of this study. Stallion F (Lusitano, 20 years old), stallion $\mathrm{G}$ (Lusitano, 5 years old), and stallion $\mathrm{H}$ (Sorraia, 10 years old) were classified as fertile ( $\mathrm{F}$ and $\mathrm{G}$ ) and infertile $(\mathrm{H})$ based on their performances in the previous breeding seasons. For these reasons data from these animals is considered separately (see Section 3 ).

Semen was routinely collected using a phantom (Hannover model) and an artificial vagina (INRA model [32]) and it was filtered through gauze to remove the gel and any large particles of debris. The gel-free semen was maintained at $35^{\circ} \mathrm{C}$ in a water-bath during dilution and semen analyses to assess sperm quality: (a) progressive motility was estimated visually under light microscopy at $35^{\circ} \mathrm{C}$ on a heated stage, (b) sperm concentration was calculated using a previously calibrated photocolorimeter at $546 \mathrm{~nm}$ (Colorimeter 254, Ciba-Corning), (c) viability (percent live sperma) was evaluated by the nigrosin-eosin stain using bright-field microscopy [33] and (d) sperm morphology was evaluated by a negative stain, using india ink as a contrasting reagent and bright-field microscopy [34].

\subsection{Artificial insemination (AI) of mares}

Semen dilution was performed at a final concentration of $20 \times 10^{6} \mathrm{sperm}$ cells $/ \mathrm{ml}$ in a milk extender medium [half skim UHT, ultra high temperature pasteurized, milk supplemented with Gentamicin $(50 \mu \mathrm{g} / \mathrm{ml})$ and Penicillin $(50 \mathrm{UI} / \mathrm{ml})]$ maintained at $35^{\circ} \mathrm{C}$ prior to semen collection. Standard doses $(15 \mathrm{ml})$ of diluted semen were used in AI within the first $30 \mathrm{~min}$ after collection.

After detecting the mare's estrus, by the observance of the estrous behaviour in the presence of a male horse, the mare's reproductive status were observed regularly by ultrasonographic scanning (5 MHz transducer) and AI took place when a $35 \mathrm{~mm}$ follicle was observed. Before inseminations the vulvar region was washed with Betadine solution. An intrauterine insemination catheter (Sonde Equine-imv Technologies) was used to deposited the semen in the uterus $(10 \mathrm{~cm}$ behind the uterine portion of the cervix) by virtue of passing the catheter through the cervix using the finger to direct it to the uterine body. Mares were inseminated with at least $300 \times 10^{6}$ spermatozoa per AI every $48 \mathrm{~h}$ until ovulation.

For diagnosis of pregnancy and twining inspection ultrasonographic images of the conceptus at 13 days after last $\mathrm{AI}$ were taken with a $5 \mathrm{MHz}$ transducer. Due to embryonic loss in early pregnancy this examination was repeated at day 45.

\subsection{Fertility rates}

To calculate the fertility rates (fertility per cycle $[\mathrm{FC}]$ and fertility at the end of the breeding season $[F]$ ) we utilized the estimations and rules commonly used in French National Studies [32]. For each stallion we determined the (1) total heat cycles (all the cycles explored), positive heat cycles (pregnant cycles determined by ultrasonography at days 13 and 45 after last AI) and negative heat cycles (non-pregnant cycles or cycles followed by a new cycle); (2) total mares, positive mares (pregnant mares) and negative 
mares (nonpregnant mares), (3) number of cycles utilized per mare inseminated and (4) number of cycles utilized per pregnancy.

\subsection{Assessment of acrosomal status}

Acrosomal integrity was evaluated by the acrosome content marker FITC-PSA (Pisum sativum agglutinin linked to fluorescein isothiocyanate) [35]. A stock solution of FITCPSA was prepared by dissolving $2 \mathrm{mg}$ of FITC-PSA in $2 \mathrm{ml}$ of Hank's balanced salt solution containing $10 \mathrm{mM}$ Hepes $(\mathrm{HH})$ and it was stored in aliquots at $-20{ }^{\circ} \mathrm{C}$. Semen sample was diluted at a final concentration of $20 \times 10^{6} \mathrm{spz} / \mathrm{ml}$ in HHBSA medium (HH plus $1 \% \mathrm{BSA}$ ) at $35^{\circ} \mathrm{C}$, fixed for $10 \mathrm{~min}$ in $2 \%$ paraformaldehyde and washed by centrifugation at $600 \times g$ for $3 \mathrm{~min}$ at $20{ }^{\circ} \mathrm{C}$. The samples were permeabilized using $95 \%$ ethanol in HHBSA (1\%) for $30 \mathrm{~min}$ at $4{ }^{\circ} \mathrm{C}$ and then washed with $\mathrm{HH}$. The samples were then incubated in FITC-PSA at a final concentration of $1 \mathrm{mg} / \mathrm{ml}$ for $15 \mathrm{~min}$ at $4{ }^{\circ} \mathrm{C}$. Sperm cells samples $(8 \mu \mathrm{l})$ were placed on glass microscope slides with coverslips and 200 cells/ ejaculate were visualized with a HUND H 600 AFL fluorescence microscope using a fluorescein filter (excitation range $450-490 \mathrm{~nm}$, dichromatic mirror $510 \mathrm{~nm}$, supression filter $520 \mathrm{~nm}$ ). Two fluorescent patterns were clearly identified: completely apple-green acrosome fluorescence (acrosome intact), and another pattern showing only a fluorescent band at the equatorial segment of the sperm head (acrosome reacted).

\subsection{Immunocytochemistry}

\subsubsection{Sperm processing for ubiquitin}

Sperm cells $\left(10 \times 10^{6} \mathrm{spz} / \mathrm{ml}\right)$ were attached to poly-L-lysine-coated microscope coverslips and fixed for $2 \mathrm{~h}$ in PBS containing 2\% formaldehyde. The samples were blocked in PBS containing 1\% BSA $+400 \mathrm{mM}$ glycine for $1 \mathrm{~h}$ and labelled overnight with the primary antibody (1:50 dilution), then washed in PBS and incubated for 60 min with the appropriate secondary antibody (1:200 dilution). The DNA stain propidium iodide was added $10 \mathrm{~min}$ before the end of incubation. Dilutions of the primary and secondary antibodies were done in blocking solution negative control samples were incubated with the secondary antibody alone. Coverslips were mounted in VectaShield mounting medium (Vector Laboratories, Burlingame, CA, USA) and 100-200 cells in each sample were visualized with a HUND H 600 AFL fluorescence microscope.

\subsubsection{Sperm processing for SNAREs and caveolin-1}

Sperm cells were attached to poly-L-lysine-coated microscope coverslips and fixed as described previously. Permeabilization was performed for $30 \mathrm{~min}$ in PBS with $1 \%$ Triton $\mathrm{X}-100$, and nonspecific reactions were blocked by further incubation in PBS containing $1 \%$ BSA and $400 \mathrm{mM}$ glycine for $1 \mathrm{~h}$ at room temperature. For labelling, samples were incubated overnight with the primary antibody diluted in blocking solution. After washing in PBS with $0.1 \%$ Triton X-100 the samples were incubated with the appropriate secondary antibody (1:200 dilution). Mounting and observations of coverslips were performed as described previously. Negative control samples were incubated with the secondary antibody alone. Alternative staining using simultaneous fixation in paraformaldehyde $(2 \%)$ 
and permeabilization with $0.1 \%$ Triton $\mathrm{X}-100$ at $37^{\circ} \mathrm{C}$ for $1 \mathrm{~h}$ was also carried out $[10,11]$ for all antibodies, with similar results (data not shown).

\subsection{Statistical analysis}

For semen quality characteristics (motility, viability, gel-free volume and total sperm number), acrosomal status and SNARE results differences between means were tested by ANOVA considering the effect of stallion (and ejaculates within any given stallion, since more than one ejaculate per stallion was used). Tukey HSD post hoc tests were performed if the initial test result was significant at $p \leq 0.05$. According to the fertility rates obtained two groups of animals were considered, fertile (stallions A and B) and in(sub)fertile (stallions $\mathrm{C}$ and D), and $t$-test was used to compare the means of positive staining cells. For morphological characteristics general differences between means were tested by an ANOVA considering effects of method (negative stain, ubiquitin), stallion (and ejaculates within any given stallion, since more than one ejaculate per stallion was used), and the interaction of stallion versus method. Differences in pregnancy cycles between groups were analysed by the chi-square $\left(\chi^{2}\right)$ test. Multiple regression was performed and we extended the ANOVA to include the semen parameters and SNARE-positive cells as sources of explained variation in fertility. Statistical significance was set at the 0.05 probability level. Results are expressed as means \pm S.D.

\section{Results}

\subsection{Clinical semen parameters and fertility results}

All semen samples were collected during the breeding season (February to July) and the ejaculates utilized to inseminate the mares, as described. Stallions A and B were highly fertile (Table 1) and all measures of seminal parameters (Table 2) were in accordance with their age. The sperm characteristics of stallion D were typical of a subfertile stallion (low percentages of viability and motility, and low sperm count), but the infertility problem observed before this study persisted, and it was therefore characterized as infertile. A malerelated problem was confirmed when mares that had failed to impregnate with samples from this male were successfully inseminated with sperm from a fertile donor. Stallion $\mathrm{C}$, the youngest one, presented the worst semen characteristics, and experienced difficulty in

Table 1

Fertility rates in four stallions of varying fertility

\begin{tabular}{lcccclll}
\hline Stallion & $\begin{array}{l}\text { Total } \\
\text { mares }\end{array}$ & $\begin{array}{l}\text { FC } \\
(\%)\end{array}$ & $\begin{array}{l}F \\
(\%)\end{array}$ & $\begin{array}{l}\text { Total } \\
\text { heat cycles }\end{array}$ & $\begin{array}{l}\text { Heat } \\
\text { cycles/mare }\end{array}$ & $\begin{array}{l}\text { Heat } \\
\text { cycles/pregnancy }\end{array}$ & Notes \\
\hline A & 20 & 79.17 & 95.0 & 24 & 1.2 & 1.26 & Fertile \\
B & 6 & 100 & 100 & 6 & 1.0 & 1.0 & Fertile \\
C & 4 & 40 & 50 & 5 & 1.25 & 2.5 & Subfertile \\
D & 7 & 0.0 & 0.0 & 14 & 2.0 & - & Infertile \\
\hline
\end{tabular}

FC: fertility per heat cycle; $F$ : fertility rate at the end of the breeding season. 
Table 2

Clinical semen parameters in four stallions of varying fertility ${ }^{a}$

\begin{tabular}{|c|c|c|c|c|c|c|c|c|}
\hline Stallion & $\begin{array}{l}\text { Age } \\
\text { (years) }\end{array}$ & $\begin{array}{l}\text { Total sperm } \\
\text { number }\left(\times 10^{9}\right)\end{array}$ & Vitality $^{\mathrm{b}}(\%)$ & $\begin{array}{l}\text { Motility }{ }^{\mathrm{c}} \\
\text { (percent progressive) }\end{array}$ & $\operatorname{Abnormal}^{\mathrm{d}}(\%)$ & Volume (gel-free) (ml) & $\mathrm{pH}$ & Notes \\
\hline A & 16 & $8.06 \pm 4.03(33)^{\mathrm{a}}$ & $73.19 \pm 12.44(26)^{\mathrm{c}}$ & $51.14 \pm 6.59$ & $16.09 \pm 3.86(11)$ & $46.18 \pm 18.06(30)^{\mathrm{e}}$ & $7.15 \pm 0.3(34)^{\mathrm{e}, \mathrm{f}}$ & Fertile \\
\hline B & 20 & $7.8 \pm 3.5(14)^{\mathrm{a}}$ & $74.83 \pm 12.02(12)^{\mathrm{c}}$ & $45.18 \pm 6.54(12)^{\mathrm{d}}$ & $11.33 \pm 3.5(9)$ & $47.25 \pm 21.71(13)^{\mathrm{e}}$ & $7.00 \pm 0.0(14)^{\mathrm{f}}$ & Fertile \\
\hline $\mathrm{C}$ & 4 & $4.6 \pm 1.8(10)^{\mathrm{b}}$ & $31.53 \pm 13.18(8)$ & $30.00 \pm 6.24(10)$ & $55.82 \pm 10.85(11)$ & $14.77 \pm 5.36(10)$ & $7.00 \pm 0.0(11)^{\mathrm{f}}$ & Sub-fertil \\
\hline $\mathrm{D}$ & 19 & $4.7 \pm 1.5(22)^{\mathrm{b}}$ & $52.36 \pm 11.82(22)$ & $40.38 \pm 7.66(20)^{\mathrm{d}}$ & $27.55 \pm 7.97(11)$ & $29.72 \pm 10.65(22)$ & $7.30 \pm 0.4(22)^{\mathrm{e}}$ & Infertile \\
\hline
\end{tabular}

Values in parentheses indicate number of ejaculates observed for each stallion. In columns with the same superscripts (a-f) the samples are not significantly different $(p<0.05)$.

${ }^{\text {a }}$ Values are means \pm S.D. of measurements.

${ }^{b}$ Values are mean $( \pm$ S.D.) percentages of the viable (not eosin stained) cells. For each ejaculate, counts were performed on 200 cells.

c Progressive motility observed after collection.

${ }^{\mathrm{d}}$ Values are mean $( \pm$ S.D.) percentages of the cells that had abnormal morphology. For each ejaculate, counts were performed on 200 cells. For statistical differences between samples see Table 3 . 
impregnating mares (2.5 heat cycles utilized per mare inseminated-Table 1$)$. This last animal belongs to a Portuguese native horse breed, the Sorraia horse, that was subject in the past to complete genetic isolation, leading to extremely high levels of inbreeding [36]. At a $5 \%$ level, a significant portion (adjusted $r^{2}=0.42$ ) of the total variance in fertility was explainable by seminal characteristics, namely by viability $(p<0.01)$.

\subsection{Ubiquitin}

The putative ubiquitin-dependent sperm quality control mechanism that resides in the mammalian epididymis [27] was very recently extended to the equine [30]. In this report, 13 ejaculates for stallion A, 6 for stallions B and C and 4 for stallion D were analysed, and a mean value of 176 cells/ejaculate were observed to determine to what extent surface ubiquitination could be related with semen quality and fertility. Although some apparently normal spermatozoa were labelled using this technique (especially for stallion D, see the following), the intensity of surface ubiquitination was highest in cells that possessed visible morphological defects on the sperm head and tail (data not shown), similarly to what has been previously reported [30].

These results were compared with the negative stain commonly used in our laboratory to routinely assess sperm morphology (Table 3). This simple method uses Indian ink to outline the cells, contrasting them against a dark background, thus allowing an easy evaluation of obvious morphological abnormalities. No significant differences were found between the results obtained with the two methods, and both seemed to inversely correlate with stallion fertility: (1) with negative staining, fertile males registered an average of $13.95 \pm 4.35 \%$ of morphologically abnormal cells, while stallions with fertility problems were found to have $41.68 \pm 17.2 \%$ of abnormal cells; (2) with ubiquitin surface staining fertile stallions registered an average of $11.54 \pm 6.62 \%$ ubiquitin-positive cells, while in(sub)fertile stallions were found to have a $34.78 \pm 13.81 \%$ staining rate. In both cases these differences were statistically significant $(p<0.001)$. However, with negative staining we found some differences between in(sub)fertile stallions, while with the ubiquitin method the differences observed were just between fertile and in(sub)fertile stallions. Additionally, we note that, for stallions A-C, the abnormal rate detected with negative staining was higher than with ubiquitin, and that for stallion $\mathrm{D}$ ubiquitin surface

Table 3

Abnormal sperm cells in four stallions of varying fertility observed by ubiquitin surface labelling and negative stain

\begin{tabular}{lllll}
\hline Spermatozoa & \multicolumn{5}{l}{ Stallion } & & \\
\cline { 2 - 5 } & $\mathrm{A}($ fertile $)$ & $\mathrm{B}$ (fertile) & $\mathrm{C}$ (sub-fertile) & D (infertile) \\
\hline Ubiquitin & $12.95 \pm 7.47$ & $8.50 \pm 2.70$ & $37.68 \pm 12.43$ & $30.44 \pm 16.51$ \\
Negative stain & $(13) \mathbf{\square}, \mathrm{b}$ & $(6) \mathbf{\square}, \mathrm{b}$ & $(6) \mathbf{O}$ & $(4) \mathrm{b}$ \\
& $16.09 \pm 3.86$ & $11.33 \pm 3.5$ & $55.82 \pm 10.85$ & $27.55 \pm 7.97$ \\
& $(11) \mathbf{O}, \mathrm{b}$ & $(9) \mathbf{O}, \mathrm{b}$ & $(11)$ & $(11) \mathrm{b}$ \\
\hline
\end{tabular}

The values are the mean $( \pm$ S.D.) percentages of the cells that had abnormal morphology. Values in parentheses indicate number of ejaculates observed for each stallion. For each ejaculate, counts were performed on 200 cells. Within a column, same letter (b) means no differences between the two methods, see text. Within a row, same mark $(\square, 0)$ denotes no differences between stallions, see text. 


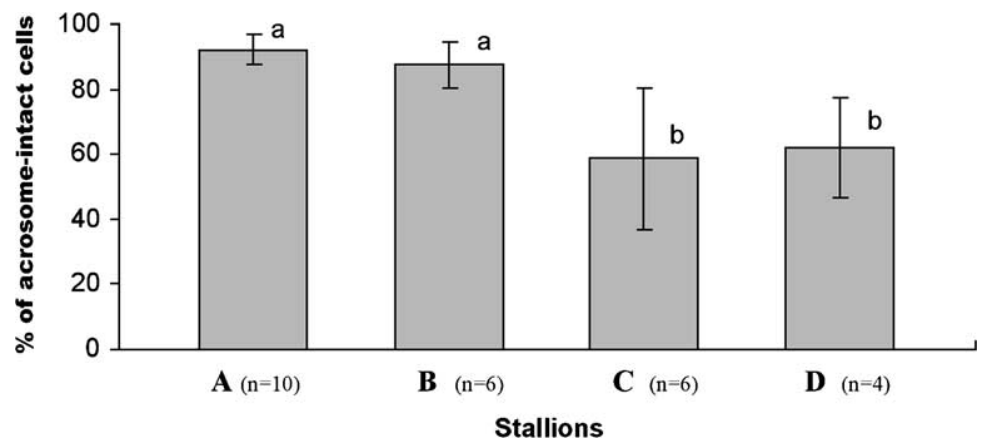

Fig. 1. Acrosome-intact spermatozoa in four stallions of varying fertility. Results represent the average \pm S.D. in percentage of measurements from 200 spermatozoa observed for each ejaculate. Same letter indicates no differences between stallions ( $\mathrm{a}$ and $\mathrm{b}, p<0.05$ ). Values in parentheses indicate number of ejaculates observed.

staining revealed a percentage of putative defective cells not detectable by the traditional method (i.e. cells stained with ubiquitin without obvious morphological defects).

\subsection{Structural integrity of the acrosome}

A proportion of $7-15 \%$ of cells with a deteriorated plasma membrane is common in freshly ejaculated equine sperm [37], and this may imply that acrosomal contents can be lost. FITC-PSA binds to the acrosomal content of spermatozoa after plasma membrane permeabilization, and thus determines the presence or absence of the acrosomal matrix, which can then be correlated with intact or reacted/damaged sperm membranes, respectively. Acrosomal status of freshly collected stallion sperm, probed using FITC-PSA, revealed intact acrosomes in $90.40 \pm 5.99 \%$ of observed cells in fertile stallions and in $60.0 \pm 18.56 \%$ cells in stallions with fertility problems $(p<0.001)$. No differences were detected between stallions A and B as well as between stallions C and D (Fig. 1). These results are gross indicators of a worse acrosomal quality for the in(sub)fertile males. Indeed, when acrosomal integrity was introduced in the model utilized to correlate semen parameters and fertility rates, a significant contribution $(p<0.05)$ to total variation in fertility was observed (adjusted $r^{2}=0.54$ ). We then attempted to probe sperm for different, functionally relevant, acrosomal proteins.

\subsection{SNAREs in equine sperm}

To better understand stallion fertility we focused our attention on SNARE-related proteins, based on previous findings that these proteins have a role in the acrosome reaction [3,11-13,38,39]. The t-SNARE syntaxin, the v-SNARE VAMP/synaptobrevin, NSF and the calcium sensor synaptotagmin were all identified on equine sperm by immunocytochemistry. Despite some variability between these proteins three major distinct cell labelling patterns were observed: (1) only equatorial labelling, (2) anterior head labelling associated with the acrosomal region and labelling in the equatorial region, (3) anterior head labelling associated with the acrosomal region only (Fig. 2). 


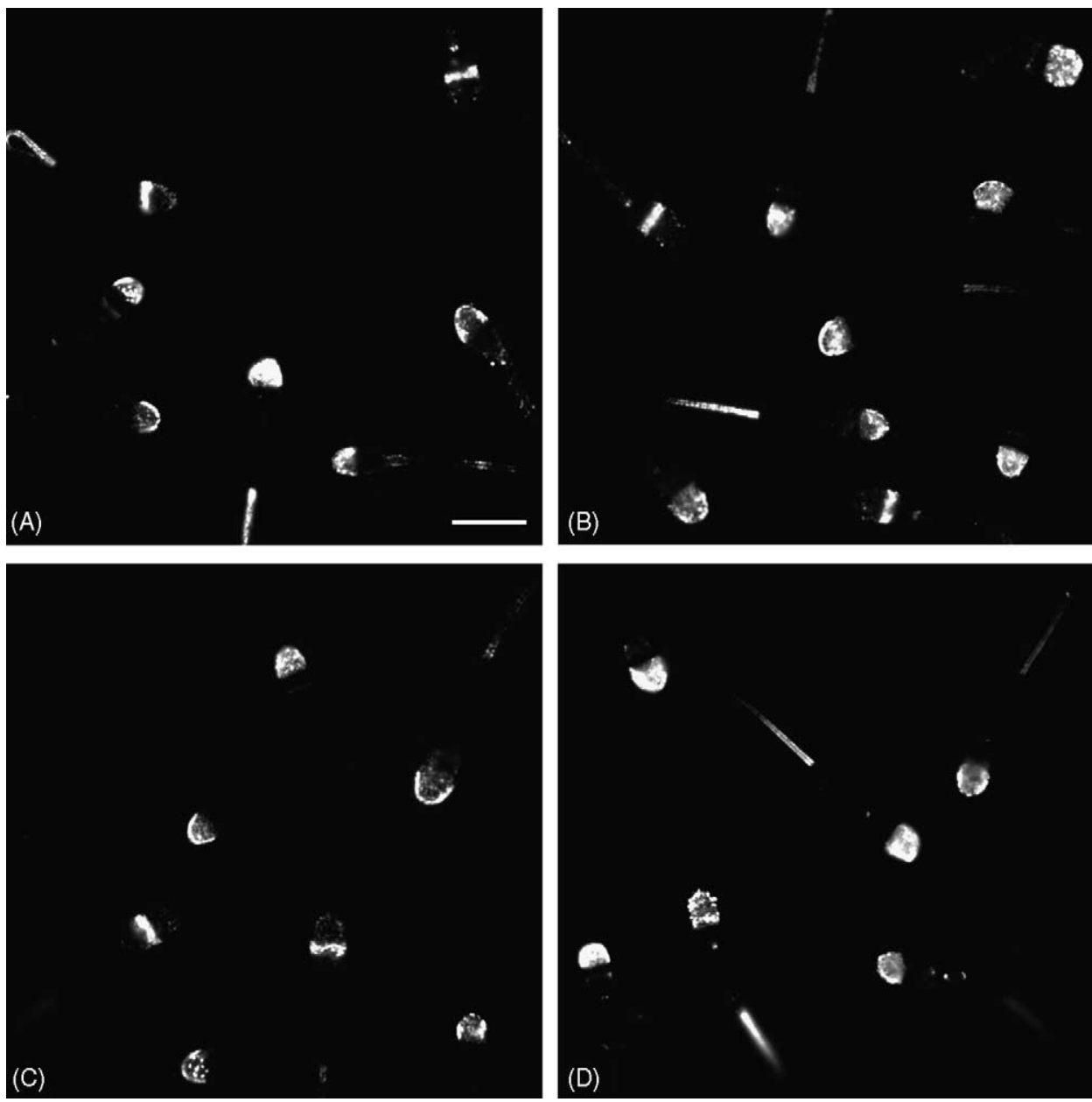

Fig. 2. SNAREs in equine sperm. VAMP/synaptobrevin, syntaxin, NSF and synaptotagmin are detected on the acrosomal cap region of the sperm head and in the equatorial segment. Syntaxin (A) and NSF (C) are detected preferentially as a halo like peripheral rim associated with mottled fluorescence labelling over the acrosomal region. Sperm preferentially show a homogeneous head label for VAMP (B) and synaptotagmin (D). Magnification $\times 100$. Bar: $5 \mu \mathrm{m}$.

Several ejaculates for each stallion and for each protein were analyzed (six to seven for stallion A, five to six for stallion B, five to six for stallion $\mathrm{C}$ and three to four for stallion D-see Table 4). For each protein an average of 120 cells were counted/ejaculate. In total, 7349 and 5706 cells were observed for fertile and in(sub)fertile stallions, respectively, and the percentage of labelled (positive) cells was calculated. Mean values of marked cells obtained with each antibody are presented (Table 4). In general, positive staining with antibodies to SNARE-related proteins was found to occur in $65.17 \pm 19.29 \%$ of cells from fertile stallions and in $42.24 \pm 22.08 \%$ of cells from in(sub)fertile males $(p<0.001)$. 
Table 4

The mean percentage for spermatozoa staining positive for SNAREs ${ }^{\mathrm{a}}$ in four stallions of varying fertility

\begin{tabular}{|c|c|c|c|c|c|}
\hline & $\begin{array}{l}\text { VAMP/ } \\
\text { synaptobrevin }\end{array}$ & Syntaxin & NSF & Synaptotagmin & Notes \\
\hline \multicolumn{6}{|l|}{ Stallion } \\
\hline A & $74.47 \pm 11.59(6) b$ & b $72.68 \pm 8.61(7) \mathrm{c}$ & $66.46 \pm 8.97$ & $85.43 \pm 8.20(7) \mathrm{e}$ & Fertile \\
\hline $\mathrm{B}$ & $34.80 \pm 6.38(5)$ & $43.62 \pm 7.72(6)$ & $48.60 \pm 8.17(5)$ & $82.83 \pm 8.98$ (6) e, $f$ & Fertile \\
\hline $\mathrm{C}$ & $19.17 \pm 8.93(6)$ & $25.95 \pm 5.45(6)$ & $32.00 \pm 3.95(6) d$ & $56.20 \pm 9.26(5)$ & Sub-fertile \\
\hline $\mathrm{D}$ & $60.59 \pm 21.09(4) b$ & b $68.75 \pm 6.09$ (4) c & $19.33 \pm 5.86(3) \mathrm{d}$ & $71.50 \pm 1.92(4) \mathrm{f}$ & Infertile \\
\hline \multicolumn{6}{|l|}{ Groups } \\
\hline Fertile & $56.44 \pm 22.64(11)$ & $59.26 \pm 18.70$ & $58.34 \pm 12.40(11)^{\text {**** }}$ & $84.23 \pm 8.31(13)^{* * * *}$ & \\
\hline In(sub)fertile & $35.74 \pm 25.50$ & $43.07 \pm 22.81$ & $27.78 \pm 7.65(9)^{* * *}$ & $63.00 \pm 10.45(9)^{* * *}$ & \\
\hline
\end{tabular}

${ }^{\mathrm{a}}$ The values are the mean ( \pm S.D.) percentages of the cells that were positively stained for SNAREs. Values in parentheses indicate number of ejaculates observed for each stallion. For each ejaculate, counts were performed on 100-200 cells. Within a column, same letters (b-f) denotes no differences between stallions; in all other cases significant differences were encountered $(p<0.05-0.001)$, see text.

*** Differences $(p<0.001)$ between groups.

Additionally, there were no significant differences between the presence and localization of these proteins before and after spontaneous sperm capacitation (data not shown). On the other hand, a relationship was observed between fertility and number of cells stained. At a $5 \%$ level, a large (adjusted $\left.r^{2}=0.87\right)$ and significant $(p<0.0001)$ portion of the variance in fertility could be explained by the number of SNARE-positive cells, namely considering synaptotagmin $(p<0.05)$ and NSF $(p<0.0001)$, as discussed in the following. Although fewer samples were available (see Section 2), similar findings were obtained with stallions $\mathrm{F}$ (fertile), $\mathrm{G}$ (fertile) and $\mathrm{H}$ (infertile) (see the following).

\subsubsection{Synaptotagmin}

Synaptotagmin appeared on the acrosome with a strong smooth fluorescence signal, not only in the acrosomal cap, but also in the equatorial region (Fig. 2D). Synaptotagmin staining seemed to be related with stallion fertility, with fertile males registering an average of $84.23 \pm 8.31 \%$ labelled cells, while stallions with fertility problems were found to have a $63.00 \pm 10.45 \%$ staining rate $(p<0.001-$ Table 4$)$. A higher percentage of synaptotagmin-positive cells were also found for the fertile stallions $\mathrm{F}$ and $\mathrm{G}(76.5 \pm 10 \%$ and $91.6 \pm 7.8 \%$, respectively), when compared to stallion $\mathrm{H}(70 \pm 3.5 \%)$.

\subsubsection{Syntaxin and VAMP/synaptobrevin}

Both proteins were localized on the acrosomal cap and the equatorial segment of equine sperm cells (Fig. 2). For syntaxin, the predominant labelling pattern was a strong halo like peripheral rim in addition to a mottled fluorescent labelling over the acrosomal region (Fig. 2A). VAMP was also confined to the same regions, but mostly with a smooth anterior head labelling pattern (Fig. 2B). The staining patterns observed are in concordance with previous work [3,38]. Within each stallion syntaxin- and VAMP-positive cells were present in the same number (i.e., no statistically significant difference was found). Also, although differences were detected between several stallions, no statistically significant difference 
was observed between fertility groups (Table 4). For stallions F, G (fertile) and H (infertile) the percentages of syntaxin-positive cells were $84.1 \pm 10.1,22.0 \pm 8.5$ and $72.7 \pm 13.5$, respectively; while they were $77.2 \pm 1.2,25.0 \pm 19.1$ and $72.7 \pm 13.5$ (respectively) for VAMP-positive cells.

\subsubsection{NSF}

Localization of NSF on the sperm acrosomal region and equatorial segment (Fig. 2C) was similar to what has been previously described $[11,40]$. Analysis performed on percentages of cells labelled for NSF indicated that fertile and in(sub)fertile stallions differed significantly ( $p<0.001$ - Table 4$)$, with fertile males registering an average of $58.34 \pm 12.40 \%$ labelled cells, while stallions with fertility problems had a $27.78 \pm 7.65 \%$ staining rate $(p<0.001-$ Table 4$)$. There were also significant individual differences between stallions $(p<0.01-$ Table 4$)$. The percentage of cells labelled with NSF was similar to that of VAMP and syntaxin $(p<0.1)$, except for the infertile stallion. In this animal we found a high number of cells stained for monomers of the SNARE complex (60.59 and $68.75 \%$ of cells displaying acrosomal staining for VAMP and syntaxin, respectively) but a low percentage of cells stained for NSF (19.33\%). A similar result was found for the infertile stallion $\mathrm{H}(17.1 \pm 3.6 \%$ of positive cells), but not for the fertile stallions $\mathrm{F}(84.0 \pm 4.2 \%)$ and $\mathrm{G}(82.6 \pm 1 \%)$. If the role of NSF is recycling SNARE monomers for subsequent rounds of fusion, and this protein is not present in the majority of the sperm cells, as seems the case for stallion D, free v- and t-SNAREs may not be available for interbilayer partnering. The capacity of rendering mares pregnant observed for the subfertile stallion could be explained on the basis that a significantly higher $(p<0.01)$ subpopulation of cells is competent to trigger acrosomal exocytosis and promote fertilization.

To determine if the low level of NSF in in(sub)fertile stallions could be the result of a high number of acrosome reacted cells we investigated if these parameters were correlated and no correlation was found. Thus, our data indicate that the low percentage of cells labelled for NSF in these stallions is an intrinsic phenomenon.

\subsection{Caveolin-1}

The presence of membrane rafts enriched in caveolin-1 in sperm was reported, and it was hypothesized that they act as scaffolds or foci for signalling pathways regulating sperm capacitation in both the head and flagellum [26]. Here we investigated the presence of caveolin-1 in equine sperm. Anti-caveolin-1 antibodies revealed strong fluorescence patterns in the same regions of the sperm cell that are enriched in cholesterol, namely at the acrosomal cap and the equatorial segment of the sperm head (Fig. 3B). Analysis of variance performed on the percentage of cells labelled with caveolin-1- (Fig. 3A) showed no differences between the two fertile stallions as well as between the stallions with fertility problems. However, caveolin-1 immunofluorescence was detected in the acrosome region of $54.30 \pm 10.02 \%$ of sperm cells in fertile males and in only $25.50 \pm 10.08 \%$ of cells in stallions with fertility problems $(p<0.001)$. Additionally, we observed that fertile stallions present a higher number of cells labelled at the equatorial region. This suggests that antibodies against caveolin-1 could help distinguish between fertile and infertile males. 


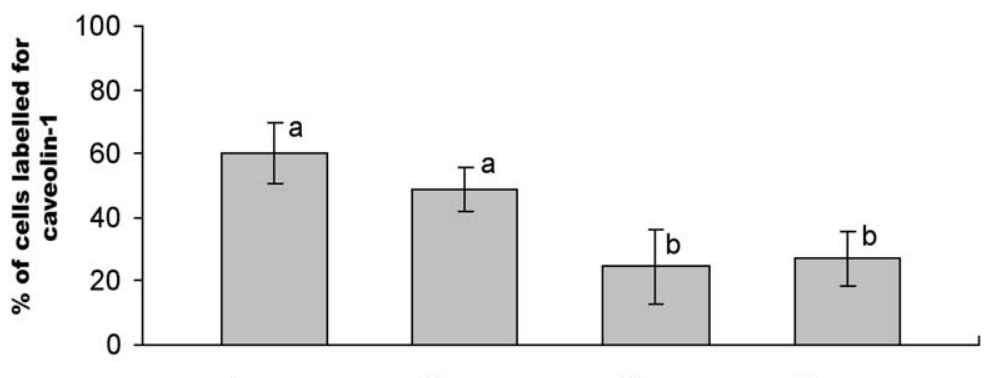

(A)
$\mathbf{A}(\mathrm{n}=5)$
$\mathbf{B}_{(\mathrm{n}=5)}$
$\mathrm{C}_{(\mathrm{n}=5)}$
$\mathbf{D}_{(\mathrm{n}=3)}$

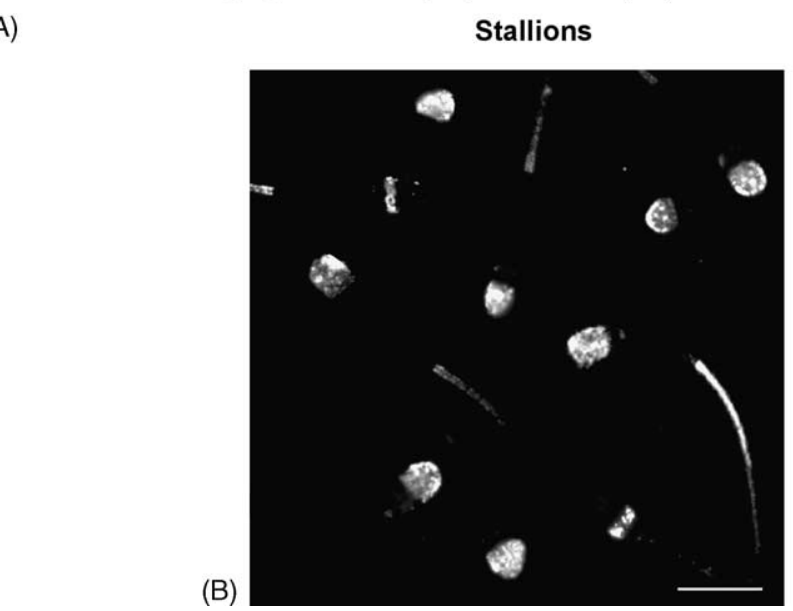

Fig. 3. (A) Presence of caveolin-1 on sperm cells of the four stallions of varying fertility. Results represent the mean \pm S.D. in percentage of cells labelled from 100 to 200 spermatozoa observed for each ejaculate. Same letter indicates no differences between stallions $(p<0.05)$. Values in parentheses beside stallions indicate number of ejaculates observed. (B) Caveolin-1 is detected in the equatorial segment and the acrosomal cap of equine sperm. Magnification $\times 100$. Bar: $5 \mu \mathrm{m}$.

\section{Discussion}

For this study we have chosen animals of varying fertility whose reproductive behaviour parameters were normal, whose seminal characteristics varied from normal to abnormal, and whose reproductive potential could be quantified directly during the study. The subfertile male presented a marginal semen profile, while the infertile stallion showed evidence of declining seminal quality (lower motility, lower viability, lower total sperm number and high level of morphologically abnormal cells). Despite the fact that stallions A and B presented ejaculates containing $\leq 60 \%$ progressively motile sperm they were highly fertile, and all the others reproductive parameters were normal. Some authors have encountered a correlation between sperm concentration, sperm motility and percentage of abnormal spermatozoa with stallion fertility [32], but, in face of the results obtained in this work, we conclude that these seminal parameters have a limited capacity in predicting stallion fertility. 
In contrast, there were significant differences in surface ubiquitination of equine sperm cells from different stallions, confirming a previous report [30]. Ubiquitin occurs universally in eukaryotic cells, and constitutes a nonlysosomal pathway for protein degradation [41]. In some mammalian species male infertility has been associated with a higher content of sperm surface ubiquitination, acquired during epididymal passage [27]. The observation that the ubiquitin method revealed a higher number of abnormal cells in the infertile stallion than were detected using the traditional (and simpler) negative staining method seems to support the idea that, besides labelling obviously defective cells, ubiquitination may occur in cells that appear morphologically normal, for reasons that are, as of yet, unclear. Morphologically abnormal spermatozoa have been related with stallion fertility and, although we have not found significant differences between the two methods, the results suggest that ubiquitin staining could reveal some novel cases of stallion infertility, regardless of the mechanism by which morphologically normal (but possibly defective) sperm are labelled.

Functional sperm undergo the exocytotic acrosome reaction, with the release of acrosomal content following fusion betweeen the outer acrosomal membrane and the plasma membrane. Recent studies indicate that components that are essential for intracellular membrane merging in somatic cells, such as SNAREs, NSF and synaptotagmins, are also present in mammalian sperm, and participate in membrane fusion events at fertilization (see [13]). In the context of the prevalent model multiple copies of free $\mathrm{v}$ - and t- SNAREs are needed to trigger fusion, and the role of SNARE proteins is to bring membranes into close apposition $[4,42]$. Studies of neuronal synapses and isolated vacuoles suggest that NSF and $\alpha$-SNAP allow docking by dissociating preexisting stable complexes of $v$ - and t-SNAREs [43]. The disruption of the SNARE complex by NSF makes SNAREs available for later rounds of fusion (for a recent review and model see [13]).

This study describes the presence of SNARE-related proteins in equine sperm, and also provides preliminary evidence that functional components of the membrane fusion machinery could be used to help predict equine fertility. Previous findings have identified these proteins in other species, and functional evidence that SNAREs could modulate secretion during the acrosome reaction has emerged [3,9-12]. In addition, members of the synaptotagmin family of calcium sensors that are active in regulated exocytosis were also described in mammalian sperm $[3,14,15]$. We have extended these findings to the equine model, although, since the probes used are known to react with several family members [13], we cannot be sure which isoforms of syntaxin, VAMP or synaptotagmin are present in this case.

Syntaxin and VAMP localized to the acrosomal cap and equatorial segment, and the number of sperm cells labelled in fertile stallions did not differ from what was found in in(sub)fertile stallions. Although these results in no way challenge the known importance of SNAREs in the acrosome reaction, they imply that quantification of syntaxin- and VAMP-positive sperm cells in a semen sample could not be used to predict the fertility problems presented by the stallions utilized in this study. On the other hand, we have also identified NSF in equine spermatozoa, and the differences encountered between stallions for NSF-positive sperm seemed to be correlated with fertility. Furthermore, the presence of NSF-positive cells was not related to acrosome integrity. In the infertile stallions ( $\mathrm{D}$ and $\mathrm{H}$ ) we found a high number of cells labelled for SNAREs, but a much lower number labelled for NSF. This observation suggests that NSF activity was possibly not sufficient to disassemble the SNARE complex. As a consequence, a majority of the sperm cells would 
probably not be competent to trigger the acrosome reaction in these cases. Similar results were obtained for synaptotagmin-positive sperm cells. Following an initial study [3], synaptotagmin VI and synaptotagmin VIII have been identified in human [14] and mouse sperm cells [15], respectively. In our equine system the high percentage of cells labelled for synaptotagmin in fertile stallions differed significantly from the average found in stallions with fertility problems, which could mean that calcium sensitivity is impaired in a significant number of sperm cells from infertile stallions.

Another essential feature of sperm biology is capacitation, which precedes the acrosome reaction. This process involves the removal of cholesterol from sperm membranes, an event connected with signal transduction $[37,44]$. Cholesterol causes dramatic changes in membrane molecular order and fluidity [45] and modulates the occurrence and structure of lipid-driven membrane domains [46,47]. It also has a critical influence in the integrity of lipid rafts [48]. We have detected caveolin-1 on the cholesterol rich-regions of equine sperm cells, the acrosomal cap and equatorial segment [49], the same localization as for SNARE proteins. Furthermore, the number of caveolin-positive cells could be used to distinguish between fertile and infertile stallions. Previous authors have suggested that the localization and/or organization of specific signalling pathways in sperm could be mediated by caveolin rafts [26], and it is possible that lack of caveolin-positive cells may impair stallion fertility by affecting these pathways.

In conclusion, prediction of stallion fertility could be improved if additional parameters were to be used. Based on our samples and observations (which will require further validation, using a larger number of animals) there appears to be a relationship between equine fertility and the presence of more or less sperm cells positively labelled for synaptotagmin (a calcium sensor), NSF (a SNARE complex disassembler) and caveolin-1 (a signalling pathways organizer). What the exact functional relevance of these observations is in terms of sperm physiology remains to be determined.

\section{Acknowledgments}

The technical assistance of Alexandra Amaral and Prof. Teresa Almeida Santos (University Hospitals of Coimbra) is gratefully acknowledged. S.G. wishes to thank C. Cravo, N. Oliveira, F. Pinto, F. Cruz, P. Gamboa, and C. Cruz for their continuous encouragement and support. J.R.-S. wishes to thank M.C.P. Lima, C.R. Oliveira. M.G.P. Vale, S.N. Almeida Santos, J.C. Marques and I. Spencer for their faith and support. This work was supported by a grant from Fundação para a Ciência e Tecnologia (FCT), Portugal (POCTI/ESP/38049/2001) with funds from FEDER to J.R.-S.

\section{References}

[1] Magistrini M, Vidament M, Clement F, Palmer E. Fertility prediction in stallions. Anim Reprod Sci 1996;42:181-8.

[2] Yanagimachi R. Mammalian fertilization. In: Knobil E, Neill JD, editors. The physiology of reproduction. New York: Raven Press; 1994. p. 189-317. 
[3] Ramalho-Santos J, Moreno RD, Sutovsky P, Chan AW, Hewitson L, Wessel GM, et al. SNAREs in mammalian sperm: possible implications for fertilization. Dev Biol 2000;223:54-69.

[4] Jahn R, Grubmuller H. Membrane fusion. Curr Opin Cell Biol 2002;14:488-95.

[5] Hay JC. SNARE complex structure and function. Exp Cell Res 2001;271:10-21.

[6] May AP, Whiteheart SW, Weis WI. Unraveling the mechanism of the vesicle transport ATPase NSF, the $N$ ethylmaleimide-sensitive factor. J Biol Chem 2001;276(25):21991-4.

[7] Coorssen J, Blank P, Tahara M, Zimmerberg J. Biochemical and functional studies of cortical vesicle fusion: the SNARE complex and $\mathrm{Ca}^{2+}$ sensitivity. J Cell Biol 1998;143:1845-57.

[8] Schiavo G, Osborne SL, Sgouros G. Synaptotagmins: more isoforms than functions? Biochem Biophys Res Commun 1998;248:1-8.

[9] Katafuchi K, More T, Toshimori K, Iida H. Localization of a syntaxin isoform, syntaxin 2, to the acrosomal region of rodent spermatozoa. Mol Reprod Dev 2000;57:375-83.

[10] Yunes R, Michaut M, Tomes C, Mayorga L. Rab3A triggers the acrosome reaction in permeabilized human spermatozoa. Biol Reprod 2000;62:1084-9.

[11] Michaut M, Tomes CN, De Blas G, Yunes R, Mayorga LS. Calcium-triggered acrosomal exocytosis in human spermatozoa requires the coordinated activation of Rab3A an $N$-ethylmaleimide-sensitive factor. Proc Natl Acad Sci USA 2000;29:9996-10001.

[12] Tomes CN, Michaut M, De Blas G, Visconti P, Matti U, Mayorga LS. SNARE complex assembly is required for human sperm acrosome reaction. Dev Biol 2002;243:326-38.

[13] Ramalho-Santos J, Schatten G, Moreno RD. Control of membrane fusion during spermiogenesis and the acrosome reaction. Biol Reprod 2002;67:1043-51.

[14] Michaut M, De Blas G, Tomes CN, Yunes R, Fukuda M, Mayorga LS. Synaptotagmin VI participates in the acrosome reaction of human spermatozoa. Dev Biol 2001;235:521-9.

[15] Hutt DM, Cardullo RA, Baltz JM, Ngsee JK. Synaptotagmin VIII is localized to the mouse sperm head and may function in acrosomal exocytosis. Biol Reprod 2002;66:50-6.

[16] Amman RP, Graham JK. Spermatozoal function. In: Mckinnon AO, Voss JL, editors. Equine reproduction. Philadelphia: Willians \& Wilkins; 1993. p. 715-45.

[17] Bearer EL, Friend DS. Modifications of anionic-lipid domains preceding membrane fusion in guinea pig sperm. J Cell Biol 1982;92:604-15.

[18] Wolf DE, Voglmayr JK. Diffusion and regionalization in membranes of maturing ram spermatozoa. J Cell Biol 1984;98:1678-84.

[19] Myles DG, Primakoff P, Koppel DE. A localized surface protein of guinea pig sperm exhibits free diffusion in its domain. J Cell Biol 1984;98:1905-9.

[20] Ladha S, James PS, Clark DC, Howes EA, Jones R. Lateral mobility of plasma membrane lipids in bull spermatozoa: heterogeneity between surface domains and rigidification following cell death. J Cell Sci 1997;110:1041-50.

[21] Simons K, Ikonen E. Functional rafts in cell membranes. Nature 1997;387:569-72.

[22] Rietveld A, Simons K. The differential miscibility of lipids as the basis for the formation of functional membrane rafts. Biochim Biophys Acta 1998;1376:467-79.

[23] Murata M, Peranen J, Schireiner R, Wieland F, Kurchalia TV, Simons K. VIP21/caveolin is a cholesterolbinding protein. Proc Natl Acad Sci USA 1995;92:10339-43.

[24] Rothberg KG, Heuser JE, Donzell WC, Ying YS, Glenney JR, Anderson RG. Caveolin, a protein component of caveolae membrane coats. Cell 1992;68:673-82.

[25] Treviño CL, Serrano CJ, Beltrán C, Felix R, Darszon A. Identification of mouse trp homologues and lipid rafts from spermatogenic cells and sperm. FEBS Lett 2001;509:119-25.

[26] Travis AJ, Merdiushev T, Vargas LA, Jones BH, Purdon MA, Nipper RW, et al. Expression and localization of caveolin-1, and the presence of membrane rafts, in mouse and guinea pig spermatozoa. Dev Biol 2001;240:599-610.

[27] Sutovsky P, Moreno R, Ramalho-Santos J, Dominko T, Thompson WE, Schatten G. A putative ubiquitindependente mechanism for the recognition and elimination of defective spermatozoa in the mammalian epididymis. J Cell Sci 2001;114:1665-75.

[28] Sutovsky P, Terada Y, Schatten G. Ubiquitin-based sperm assay for the diagnosis of male factor infertility. Hum Reprod 2001;16(2):250-8. 
[29] Sutovsky P, Neuber E, Schatten G. Ubiquitin-dependent, sperm quality control mechanism recognizes spermatozoa with DNA defects, as revealed by dual ubiquitin-TUNEL assay. Mol Reprod Dev 2002;61:40613.

[30] Sutovsky P, Turner RM, Hamed S, Sutovsky M. Differential ubiquitination of stallion sperm proteins: possible implications for infertility and reproductive seasonality. Biol Reprod 2003;68:688-98.

[31] Palmer E, Fauquenot A. Mesure and prediction de la fertilité des étalons. Etude méthodologique. In: Jarnige R, Martin-Rosset W, editors. Le Cheval. Reproduction, selection, alimentation, explotation. Paris: INRA; 1984. p. 113-27.

[32] Insémination Artificielle Équine, Guide Pratique. Ministère de L'Agriculture, de La Pêche et de l'Alimentation. Service des Haras, des Courses et de l'Equitation. Ed Institut du Cheval, 2e éd. France; 1996.

[33] Bloom E. A one minute live-dead sperm stain by means of eosin-nigrosin. Fertil Steril 1950;1:176-7.

[34] Foote RH. Effect of processing and measuring procedures on estimated size of bull sperm heads. Theriogenology 2003;59:1765-73.

[35] Guitton E. Capacitation des spermatozoids equines: mesure de l'influx de calcium par cytométrie en flux. Mémoire de DEA Biomembranes. Limoges, Tours: Université de Poitiers; 1996.

[36] Oom MM, Luís C. The Sorraia Horse (Portugal): genetic variation and genetic management of an endangered breed. IIIe Cycle Romand en Sciences Biologiques. Conservation Genetics Meeting, 2001.

[37] Flesch FM, Gadella BM. Dynamics of the mammalian sperm plasma membrane in the process of fertilization. Biochim Biophys Acta 2000;1469:197-235.

[38] Schulz JR, Wessel GM, Vacquier V. The exocytosis regulatory proteins syntaxin and VAMP are shed from Sea Urchin sperm during the acrosome reaction. Dev Biol 1997;191:80-7.

[39] Kierszenbaun A. Fusion of membranes during the acrosome reaction: a tale of two SNAREs. Mol Reprod Dev 2000;57:309-10.

[40] Ramalho-Santos J, Schatten G. Presence of $N$-ethyl malameide sensitive factor (NSF) on the acrosome of mammalian sperm. Arch Androl 2004;50:163-8.

[41] Zubay GL. Biochemistry. Dubuque, IA: W m. C. Brown Publishers; 1998.

[42] Weber T, Zemelman BV, McNew JA, Westermann B, Gmachl M, Parlati F, et al. SNAREpins: minimal machinery for membrane fusion. Cell 1998;92:759-72.

[43] Ungermann C, Nichols BJ, Pelham H, Wickner W. Vacuolar v-t-SNARE complex, the predominant form in vivo and on isolated vacuolos, is disassembled and activated for docking and fusion. J Cell Biol 1998;140:61-9.

[44] Breitbart H, Naor Z. Protein kinases in mammalian sperm capacitation and the acrosome reaction. Rev Reprod 1999;4:151-9.

[45] Vist MR, Davis JH. Phase equilibria of cholesterol/dipalmitoylphosphatidylcholine mixtures: ${ }^{2} \mathrm{H}$ Nuclear magnetic resonance and differential scanning calorimetry. Biochemistry 1990;29:451-64.

[46] Lewis RNAH, McElhaney RN. The mesomorphic phase behaviour of lipid bilayers. In: The structural of biological membranes. London/Boca Raton: Philip Yagle/CRC Press; 1992.

[47] Williams EE. Membrane lipids: what membrane physical properties are conserved during physiochemicallyinduced membrane restructuring? Am Zool 1998;38:280-90.

[48] Keller P, Simons K. Cholesterol is required for surface transport of influenza virus hemagglutinin. J Cell Biol 1998;140:1357-67.

[49] Friend DS. Plasma-membrane diversity in a highly polarized cell. J Cell Biol 1982;93:243-9. 